\title{
Possible mechanism of neointima formation in pulmonary arterial hypertension
}

\author{
Rajamma Mathew* \\ Section of Pediatric Cardiology, Department of Physiology, New York Medical College, Valhalla, New York, USA
}

\begin{abstract}
Pulmonary arterial hypertension $(\mathrm{PAH})$ is a serious sequel of a number of systemic diseases including cardiopulmonary, inflammatory and autoimmune diseases. Endothelial disruption/dysfunction plays a significant role in the initiation and the progression of the disease. Although modern therapy has improved the quality of life, but the underlying vascular disease progresses unabated; and the survival rate has not improved significantly. The major pathological changes are impaired vascular relaxation response, medial hypertrophy, increased pulmonary pressure; subsequent neointimal formation results in the irreversibility of the disease. Progressive loss of endothelial caveolin-1 (cav-1), a membrane protein has been shown to be associated with reciprocal activation of proliferative pathways and initiation of $\mathrm{PAH}$. Subsequent disruption of endothelial cells and endothelial cav-1 is accompanied by enhanced expression of cav- 1 in smooth muscle cells where it becomes proproliferative. This review examines the dual role of cav-1 as a possible contributory mechanism of neointima formation.
\end{abstract}

\section{Introduction}

Ernst von Romberg, in 1891 described histological changes in the lungs as pulmonary vascular sclerosis; considered to be the first description of pulmonary hypertension (PH). In 1901, Abel Ayerza described a patient with dyspnea, cyanosis, right ventricular failure and pulmonary vascular sclerosis. For several years, the disease was called "Ayerza's disease" [1,2]. Since then, a significant progress has been made in the field, but the mechanism/s of $\mathrm{PH}$ is still not completely understood. A number of systemic diseases such as cardiopulmonary, systemic, infection, inflammatory and autoimmune diseases, hematological disorders and drug toxicity have been shown to lead to $\mathrm{PH}$. PH has been classified into 5 major clinical groups, that was updated in 2013 [3]. The group 1 is labeled as pulmonary arterial hypertension $(\mathrm{PAH})$ that includes idiopathic, heritable $\mathrm{PAH}$, and $\mathrm{PAH}$ secondary to congenital heart defect, drug toxicity, inflammation and autoimmune diseases. Survival of PAH patients without treatment is estimated to be 2.8 years [4]. Modern therapy has improved the quality of life, however, underlying vascular disease progresses unabated [5]. In the PAH patients, one-year survival is $85 \%$ and the 3 -year survival is $58 \%[6,7]$. The diagnosis of $\mathrm{PAH}$ is made when the mean pulmonary artery pressure is $\geq 25 \mathrm{mmHg}$, pulmonary capillary wedge pressure $\leq 15 \mathrm{mmHg}$, and a pulmonary vascular resistance $>3$ Wood units at rest. Loss or increased expression of molecule/s secondary to an injury affects the delicate network of signaling pathways leading to deregulated inflammatory response, cell proliferation, cell migration and angiogenesis resulting in the initiation and progression of $\mathrm{PAH}$ [8]. The sequence of events in PAH has been described as medial hypertrophy, cellular intimal proliferation, concentric laminar intimal fibrosis fibrinoid necrosis, dilatation and plexiform lesions. Furthermore, the pulmonary vascular lesions were found to be similar to primary pulmonary hypertension and PAH associated with congenital heart defect [9]. Importantly, children with congenital heart defect (left to right shunts) who underwent pulmonary artery banding to restrict pulmonary flow showed reversal of pulmonary vascular changes. Medial hypertrophy and early intimal changes appeared reversible; but the later stages were not reversible [10,11]. Regardless of the underlying disease, the major features of $\mathrm{PH}$ are 1) endothelial dysfunction/ disruption leading to impaired vascular relaxation response and the activation of proliferative and antiapoptotic pathways; 2) smooth muscle cell proliferation, medial thickening, narrowing of the lumen, elevation of pulmonary artery pressure, and 3) right ventricular hypertrophy. As the disease progresses, smooth muscle cell (SMC) phenotype changes from contractile to synthetic, and participate in cell migration, and neointima formation resulting in arterial occlusive disease leading to RV failure and premature death. Neointima formation leads to the irreversibility of the disease [12].

An intricate interaction exists among a large number of signaling molecules in pulmonary vasculature to maintain homeostasis. Deregulation of multiple factors contributes to PAH. Endothelial dysfunction, impaired vascular dilatation, alterations in the expression of NO, ET1 and serotonin, increased expression of inflammatory cytokines and chemokines and disordered proteolysis of extracellular matrix contribute to the pathogenesis of PAH [13]. Furthermore, perivascular infiltration with inflammatory cells ( $\mathrm{T}$ and $\mathrm{B}$ cells) in plexiform lesions has been reported [14,15]. In addition to the imbalance of vasoactive mediators and vascular remodeling, abnormality in ion channels $\left(\mathrm{Ca}^{2+}, \mathrm{K}^{+}\right)$, and Growth factors such as VEGF, EGF, TGF beta, MMPs, BMPR2 and Notch, cytokines have been implicated in pathogenesis of $\mathrm{PAH}$ [16]. There are no animal models which can accurately depict human PAH. This is not surprising because a large

${ }^{\star}$ Correspondence to: Rajamma Mathew MD, Section of Pediatric Cardiology and Physiology, Basic Science Building, New York Medical College, Valhalla, New York, USA, Tel: 914-594-4750; E-mail: rajamma_mathew@nymc.edu

Key words: caveolin-1, endothelial injury, neointima, pulmonary hypertension

Received: December 03, 2018; Accepted: December 10, 2018; Published: December 13, 2018 
number of unrelated diseases lead to PAH. Furthermore, in animal models, the species variations can affect the pathological alterations; and the results are dependent on the duration of the study, and the rate of development of the pathological changes in the vasculature. Despite these limitations, the animal models of $\mathrm{PH}$ have contributed a great deal to the understanding of the disease and have been quite useful for preclinical drug testing for efficacy and safety $[17,18]$. The diagnosis of PAH is often delayed because of vague symptoms; and initial pathological changes are not clinically identifiable. Interestingly, in an animal model of $\mathrm{PH}$, significant molecular and pathological changes have been shown to occur before the onset of $\mathrm{PH}$ [19]

\section{Pulmonary Hypertension Models}

Monocrotaline (MCT), a toxic pyrrolizidine compound obtained from the seeds and leaves of Crotalaria Spectabilis has been used to induce PH in animals. MCT is converted to dehydromonocrotaline (DHMC) in the liver by cytochrome 450 . The half-life of DHMC in the rat serum is about 5 seconds. A large dose results in acute liver injury and death within a few days. A small dose induces transient liver injury; and during the first passage through the lungs DHMC damages the endothelial cells leading to pulmonary vascular changes [20]. MCTinduced $\mathrm{PH}$ in rats is an extensively-studied model. In rats, a single sc injection of $60 \mathrm{mg} / \mathrm{kg}$ induces progressive endothelial disruption and endothelial caveolin-1 ((cav-1) loss accompanied by the reciprocal activation of proliferative and anti-apoptotic pathways such as PYSTAT3, and Bcl-xL before the onset of PH [19]. Loss of other membrane proteins such as Tie2, PECAM-1, soluble guanylate cyclase ( $\alpha$ and $\beta$ ) occur in tandem with endothelial cav-1 loss, indicating a generalized endothelial membrane disruption. A further loss of endothelial cav-1 is accompanied by $\mathrm{PH}$ and right ventricular hypertrophy and NF- $\mathrm{kB}$ activation at 2 weeks post-MCT. In addition, a significant reduction in the expression of several cytosolic proteins such as I- $\mathrm{kBa}$, HSP90, Akt and protein-bound sulfhydrils and the levels of cGMP is observed at this stage [21,22]. Progressively increasing expression and activity of MMP2 are present at 2 and 4 weeks post-MCT [23]. In addition, increased synthesis of collagen and insoluble elastin has been reported in the MCT model [24]. However, neointima formation has not been reported in MCT-treated rats

In dogs, dehydromonocrotaline (DHMC) has been used as an intra-atrial injection to induce $\mathrm{PH}$, because the dog liver lacks the enzyme that converts MCT to DHMC. Eight weeks after intra-atrial injection of DHMC (3 mg/kg), beagle dogs (age 12 weeks) developed significant $\mathrm{PH}$, pulmonary vascular remodeling, including medial wall and adventitial thickening and neointima formation and right ventricular hypertrophy $[25,26]$. Similarly, adult mongrel dogs, given an injection of DHMC $(3 \mathrm{mg} / \mathrm{kg})$ developed $\mathrm{PH}$, thickened medium sized arterioles and obliterated small arteries [27]. It is interesting to note that neointima formation has not been observed in rats; but in dogs, neointimal lesions have been reported after DHMC injection. Since dogs were studied 8 weeks after the DHMC injection and the rats are usually examined 2- 4 weeks after the MCT injection, it is likely that the duration of the endothelial disruption and increased pressure may have a role in the development of neointima. Although, in rats, MCT alone has not produced neointima lesion, but a second hit such as increased pulmonary blood flow or hypoxia has resulted in neointima formation.

\section{a. MCT + Pneumonectomy/Increased pulmonary blood flow}

Increased blood flow in addition to MCT-induced endothelial damage and $\mathrm{PH}$ has been shown to result in neointima formation. Right pulmonary artery remodeling in MCT plus pneumonectomy animals was compared with animals receiving MCT or pneumonectomy alone.
Neointimal changes developed in more than $90 \%$ of all right lung intraacinar vessels 5 weeks after MCT injury ( 4 weeks after pneumonectomy). Neointimal lesions did not develop in untreated animals or in animals receiving MCT or pneumonectomy only. Animals with a neointimal pattern of remodeling developed severe right ventricular hypertrophy (RVH) whereas animals with a medial hypertrophy pattern of remodeling (MCT only group) developed moderate RVH compared with control animals. Neointimal lesions and RVH were similar whether MCT injury preceded pneumonectomy or followed it. To exclude the possibility that neointimal lesions resulted from injury plus post-pneumonectomy rather than injury plus increased flow, a left subclavian-pulmonary artery anastomosis was substituted for pneumonectomy. Neointimal lesions and severe RVH developed in these animals but were not seen in animals receiving either MCT or anastomosis only. These studies demonstrate an important role for hemodynamic alteration in determining the pattern of pulmonary vascular remodeling after injury $[28,29]$. Furthermore, in this model, increased expression of tissue factor and the membrane glycoprotein that initiate coagulation and angiogenesis have been reported [30]. In addition, increased oxidative stress, increased expression of cytokines and NOX4 and MnSOD, infiltration of pulmonary arterial wall with inflammatory, and $\mathrm{CD}^{+} / 8^{+}$vimentin ${ }^{+}$cells were observed [31]. In another study abdominal aorto-pulmonary shunt was performed a week before MCT injection; 4-5 weeks later increased mortality, and neointimal lesions were observed [32]. These studies indicate the increased pulmonary blood flow in the presence of damaged endothelium leads to severe pulmonary vascular changes.

\section{b. MCT + hypoxia}

Exposing MCT-injected rats to hypoxia results in acceleration of the disease process and neointima formation. Importantly, the neointimal lesions stained positive for $\alpha$-actin but not vWF [33,34], indicating SMC migration into neointima. Significant loss of endothelial cav1 and enhanced expression of cav-1 in SMC has been observed. Enhanced expression of cav-1 in SMC is observed only in arteries displaying extensive loss of endothelial cav- 1 at 4 weeks. Furthermore, neointimal lesions were seen only in the arteries exhibiting extensive endothelial cav-1 loss accompanied by enhanced expression of cav-1 in SMC. Importantly, similar changes were observed in human PAH [35]. Interestingly, SMC from patients with idiopathic $\mathrm{PAH}$ in in-vitro study showed enhanced expression of cav-1, increased capacitative $\mathrm{Ca}^{2+}$ entry and DNA synthesis, which could be abrogated by silencing cav-1 [36]. These results underscore the dual role of cav-1 in the pathogenesis of PAH and the irreversibility.

\section{Sugen + Hypoxia}

Sugen 5461, a VEGF receptor blocker has been used to induce PAH. Rats were given an injection of Sugen and exposed to hypoxia for 3 weeks; and then reverted to normoxic atmosphere. After exposure to normoxia, polycythemia reverted to normal, PAP decreased a little, but the vascular changes continued, and by 13-14 weeks after sugen injection plexiform lesions were observed [37-39]. Interestingly, unilateral PA band resulted in prevention and also reversal of pulmonary vascular changes [40]. These studies further support the view that the endothelial damage in the presence of increased pressure/ flow results in progressive vascular changes.

\section{Shunt Models}

Congenital heart defects with large left to right shunts at the ventricular septal or at the ductus, if not repaired early, leads to 
pulmonary hypertension and reversal of the shunt, known as Eisenmenger syndrome. Larger animals such as dogs and pigs have been used to study the progression of PAH in shunt defects. Modified Blalock-Taussig or Pott shunt has been used to study the pulmonary vascular alteration during the development of shunt-induced PAH. Similar to clinical cases, a small shunt resulted in medial hypertrophy, and a larger shunt led to obliterative lesions in pulmonary arteries. Large shunt was shown to lead to fatal heart failure. Two dogs with shunt sizes of 1 and $4 \mathrm{~mm}$ revealed PA medial wall thickness, whereas a shunt size of $5 \mathrm{~mm}$ in a younger dog revealed medial wall thickness and plexiform lesions 20 months after the shunt [41]. Esterly et al [42] attached left subclavian artery to left pulmonary artery; 2 weeks later, lower left lobe was ligated to increase the flow to the upper lobe. The sequential biopsy revealed both EC and SMC to be hyperactive and there was increased sub-endothelial space at 4 weeks. At 2-4 months, there was focal intimal thickening, EC degeneration, SMC extending into sub-intimal space through gaps in internal elastic lamina and accumulation of cells in intima, followed by occlusive lesions and poorly differentiated SMC at 4 months. In left subclavian to left pulmonary artery shunt model (to one lung or a lobe) revealed muscular hypertrophy at 2 weeks after the shunt; intimal proliferation and adventitial thickening appeared 2-3 months later. The vascular changes were more when systemic to pulmonary artery was end to end rather than when the shunt was connected to the MPA [43]. Furthermore, aorta-pulmonary artery shunt to whole lung did not develop any lesions; but restricted shunt to the lower lobe resulted in significant changes after 4 weeks of shunt. Medial hypertrophy was reversible, but grade IV changes did not reverse on removing the shunt [44]. Similarly, aorta-left pulmonary artery or left lobar artery resulted in pulmonary arterial hypertension, vascular occlusive and plexiform lesions [45-47]. These studies show similar to what has been observed clinically. It is likely that increased flow in the presence of increased pressure incurs endothelial damage.

\section{Miscellaneous}

Partial lung radiation in rats has been shown to result in significant EC loss, perivascular edema followed by pulmonary vascular remodeling including neointima formation, $\mathrm{PAH}$ and right ventricular hypertrophy [48]. Interestingly, extensive vascular injury caused by balloon endartectomy itself can lead to the development of neointimal lesions [29]. Thus, extensive endothelial damage can progress to neointima formation.

\section{Possible Mechanism of Neointima Formation}

Endothelial Function: Endothelium, a semi-permeable monolayer is an interface between the media (smooth muscle cells) and circulation. It maintains a balance between vasoconstriction and vasodilatation, and between cell proliferation and apoptosis. In addition, it provides barrier function, and balances pro- and anticoagulation factors of the vessel wall and participates in immune function. Plasmalemmal membrane of the endothelial cells have specialized microdomains such as caveolae, rich in cholesterol and sphingolipids that serve as a platform for a numerous signaling molecules and compartmentalize them for optimum function. In addition to EC, caveolae are found on a number of cells such as SMC, epithelial cells and fibroblasts. Caveolin-1, a major protein constituent of caveolae maintains the shape of caveolae and interacts with numerous signaling molecules that reside in or recruited to caveolae; stabilizes them and keeps these molecules in an inhibitory conformation. A large number of signaling pathways implicated in $\mathrm{PH}$ have been shown to interact with endothelial caveolin-1. Therefore, endothelial dysfunction including the loss of functional endothelial caveolin-1 induced by injury such as inflammation, toxicity, increased shear stress and hypoxia etc., may be the initiating factor in the pathogenesis of $\mathrm{PH}$ and also contributing to the progression of the disease [49].

Caveolin-1 interacts, regulates and stabilizes several proteins including Src family of kinases, G-proteins (a subunits), G proteincoupled receptors, H-Ras, PKC, eNOS, integrins and growth factor receptors such as VEGF-R, EGF-R, PDGF-R. Caveolin-1 exerts negative regulation of the target protein within caveolae, through caveolin-1scaffolding domain (CSD, residue 82-101). Major ion channels such as $\mathrm{Ca}^{2+}$-dependent potassium channels and voltage-dependent $\mathrm{K}^{+}$ channels (Kv1.5), and a number of molecules responsible for $\mathrm{Ca}^{2+}$ handling such as inositol triphosphate receptor $\left(\mathrm{IP}_{3} \mathrm{R}\right)$, heterodimeric GTP binding protein, $\mathrm{Ca}^{2+}$ ATPase and several transient receptor potential channels localize in caveolae and interact with caveolin-1. Production of vasodilators such as nitric oxide (NO), prostacyclin $\left(\mathrm{PGI}_{2}\right)$ and endothelium-derived relaxing factor [EDHF] within caveolae are dependent on caveolin-1-mediated regulation of $\mathrm{Ca}^{2+}$ entry $[50,51]$. Thus cav-1 plays a critical role in maintaining vascular homeostasis.

Disruption of EC, Loss of Endothelial cav-1 \& Enhanced Expression of Cav-1 in SMC: Increased circulating EC have been reported in patients with $\mathrm{PAH}$, indicative of EC destruction [52,53]. Recent studies have shown that the endothelial damage and loss of endothelial cav-1plays a critical role in the initiation and the progression of $\mathrm{PH}$ [54]. Interestingly, cav-1 knockout mice develop $\mathrm{PH}$, and cav-1 re-expression attenuates $\mathrm{PH}[55,56]$. In addition, Cav-1 polymorphism has been reported in patients with PAH [57]. Loss of endothelial cav-1 has been reported to be accompanied by reciprocal activation of proliferative and antiapoptotic pathways leading to medial hypertrophy and pulmonary hypertension. In addition, increased expression and activity of MMP2 was observed. Importantly cav-1 modulates MMP2 expression [23]. MMP2 induces degradation of matrix, and facilitates cell migration; and importantly, increased MMP2 expression has been reported in idiopathic PAH [58,59]. In the MCT + hypoxia model, by 4 weeks, progressive loss of endothelial cav-1 and disruption/loss of cav-1 is accompanied by enhanced expression of cav-1 in SMC, and the presence of neointimal lesions in a few arteries [35]. This cav-1 has been found to be pro-proliferative [36]. Similar changes have been reported in different forms of $\mathrm{PAH}$ such as idiopathic PAH, heritable $\mathrm{PAH}$ [35], $\mathrm{PAH}$ associated with drug toxicity [60] and with congenital heart defect [61]. Interestingly, in patients with chronic obstructive pulmonary disease (COPD) and associated $\mathrm{PH}$, loss of endothelial cav-1 accompanied by enhanced expression of cav-1 in SMC has been reported. COPD without $\mathrm{PH}$ did not exhibit cav-1 abnormalities [62]. It is worth noting here that pulmonary arterial SMC from idiopathic $\mathrm{PAH}$ revealed increased cav1 expression and increased DNA synthesis, which could be abrogated by silencing cav-1 [36]. Furthermore, neointimal lesions are seen only in the arteries that exhibit extensive loss of endothelial cav-1 and disruption of EC and enhanced expression of cav-1 in SMC. It is likely that similar to what is observed in cancer, this cav-1 in SMC facilitates cell proliferation and cell migration thus participates in neointima formation. Furthermore, EC in neointimal lesions have been found to be apoptosis resistant $[63,64]$; with low cav-1 expression [35] and increased VEGF expression, resulting in deregulated angiogenesis [65]. Thus, the dual role of cav-1 PAH may have a critical role in neointima formation and progression of the disease towards irreversibility.

In summary, endothelial damage associated with increased pulmonary flow or pressure leads to progression of PAH. Reducing 
the flow or pressure by pulmonary artery band results in the reversal of the disease if the vascular changes are relatively mild. Significant late changes are not reversible. Dual role of cav-1 plays an important role in the progression of the disease. The loss of endothelial cav-1 and the reciprocal activation of proliferative and anti-apoptotic pathways leads to the initiation and the progression of the disease. Extensive loss of endothelial cav-1 and disruption of EC is followed by enhanced expression of cav-1 in SMC and neointima formation.

\section{Acknowledgement}

RM is in part supported by Cardiovascular Medical Research and Education Fund.

\section{References}

1. Fishman AP (2004) Primary pulmonary arterial hypertension: a look back. J Am Coll Cardiol 43: 2S-4S. [Crossref]

2. Mazzei JA, Mazzei ME (2011) A tribute: Abel Ayerza and pulmonary hypertension. Eur Respir Rev 20: 220-221. [Crossref]

3. Simonneau G, Gatzoulis MA, Adatia I, Celermajer D, Denton C, et al. (2013) Updated clinical classification of pulmonary hypertension. $\mathrm{J} \mathrm{Am}$ Coll Cardiol 62: D34-41. [Crossref]

4. D’Alonzo GE, Barst RJ, Ayres SM, Bergofsky EH, Brundage BH, et al. (1991) Survival in patients with primary pulmonary hypertension. Results from a national prospective registry. Ann Intern Med 115: 343-349. [Crossref]

5. Pogoriler JE, Rich S, Archer SL, Husain AN (2012) Persistence of complex vascular lesions despite prolonged prostacyclin therapy of pulmonary arterial hypertension. Histopathology 61: 597-609. [Crossref]

6. Humbert M, Sitbon O, Chaouat A, Bertocchi M, Habib G, et al. (2010) Survival in patients with idiopathic, familial, and anorexigen-associated pulmonary arterial hypertension in the modern management era. Circulation 122: 156-163. [Crossref]

7. Thenappan T, Shah SJ, Rich S, Gomberg-Maitland M (2007) A USA-based registry for pulmonary arterial hypertension: 1982-2006. Eur Respir J 30: 1103-1110. [Crossref]

8. Mathew R (2013) Pathogenesis of pulmonary hypertension: in Pulmonary Hypertension. Editors: Elwing JM and Panos RJ. Publ: Intech: 2013: (Chapter 3, pg 47-73). ISBN 978-953-51-1165-8.

9. Yamaki S, Wagenvoort CA (1985) Comparison of primary plexogenic arteriopathy in adults and children. A morphometric study in 40 patients. Br Heart J 54: 428-434. [Crossref]

10. Dammann JF Jr, McEachen JA, Thompson WM Jr, Smith R, Muller WH Jr (1961) The regression of pulmonary vascular disease after the creation of pulmonary stenosis. $J$ Thorac Cardiovasc Surg 42:722-734. [Crossref]

11. Wagenvoort CA, Wagenvoort N, Draulans-Noë Y (1984) Reversibility of plexogenic pulmonary arteriopathy following banding of the pulmonary artery. $J$ Thorac Cardiovasc Surg 87:876-886. [Crossref]

12. Sakao S, Miyauchi H, Voelkel NF, Sugiura T, Tanabe N, et al. (2015) Increased Right Ventricular Fatty Acid Accumulation in Chronic Thromboembolic Pulmonary Hypertension. Ann Am Thorac Soc 12: 1465-1472. [Crossref]

13. Humbert M, Morrell NW, Archer SL, Stenmark KR, MacLean MR, et al. (2004) Cellular and molecular pathobiology of pulmonary arterial hypertension. $J$ Am Coll Cardiol 43:13S-24S. [Crossref]

14. Tuder RM, Groves B, Badesch DB, Voelkel NF (1994) Exuberant endothelial cell growth and elements of inflammation are present in plexiform lesions of pulmonary hypertension. Am J Pathol 144:275-85. [Crossref]

15. Stacher E, Graham BB, Hunt JM, Gandjeva A, Groshong SD, et al. (2012) Modern age pathology of pulmonary arterial hypertension. Am J Respir Crit Care Med 186: 261-272. [Crossref]

16. Schermuly RT, Ghofrani HA, Wilkins MR, Grimminger F (2011) Mechanisms of disease: pulmonary arterial hypertension. Nat Rev Cardiol 8:443-455. [Crossref]

17. Naeije R, Dewachter L (2007) [Animal models of pulmonary arterial hypertension]. Rev Mal Respir 24: 481-496. [Crossref]

18. Stenmark KR, Meyrick B, Galie N, Mooi WJ, McMurtry IF (2009) Animal models of pulmonary arterial hypertension: the hope for etiological discovery and pharmacological cure. Am J Physiol Lung Cell Mol Physiol 297: L1013-L1032. [Crossref]
19. Huang J, Wolk JH, Gewitz MH, Mathew R (2010) Progressive endothelial cell damage in an inflammatory model of pulmonary hypertension. Exp Lung Res 36: 57-66. [Crossref]

20. Roth RA, Reindel JF (1991) Lung vascular injury from monocrotaline pyrrole, a putative hepatic metabolite. Adv Exp Med Biol 283: 477-87. [Crossref]

21. Huang J, Kaminski PM, Edwards JG, Yeh A, Wolin MS, et al. (2008) Pyrrolidine dithiocarbamate restores endothelial cell membrane integrity and attenuates monocrotaline-induced pulmonary artery hypertension. Am J Physiol Lung Cell Mol Physiol 294: L1250-L1259. [Crossref]

22. Mathew R, Yuan N, Rosenfeld L, Gewitz MH, Kumar A(2002) Effects of monocrotaline on endothelial nitric oxide synthase expression and sulfhydryl levels in rat lungs. Heart Dis 4:152-158. [Crossref]

23. Huang J, Wolk JH, Gewitz MH, Mathew R (2012) Caveolin-1 expression during the progression of pulmonary hypertension. Exp Biol Med (Maywood) 237: 956-965. [Crossref]

24. Todorovich-Hunter L, Johnson DJ, Ranger P, Keeley FW, Rabinovitch M (1988) Altered elastin and collagen synthesis associated with progressive pulmonary hypertension induced by monocrotaline. A biochemical and ultrastructural study. Lab Invest 58:184-195. [Crossref]

25. Okada M, Yamashita C, Okada M, Okada K (1995) A dehydromonocrotaline-induced pulmonary hypertension model in the beagle. J Thorac cardiovascular Surg 110: 546547. [Crossref]

26. Gust R, Schuster DP (2001) Vascular remodeling in experimentally induced subacute canine pulmonary hypertension. Exp Lung Res 27:1-12. [Crossref]

27. Chen EP, Bittner HB, Craig DM, Davis RD Jr, Van Trigt P (1997) Pulmonary hemodynamics and blood flow characteristics in chronic pulmonary hypertension. Ann Thorac Surg 63: 806-813.

28. Okada K, Tanaka Y, Bernstein M, Zhang W, Patterson GA, et al. (1997) Pulmonary hemodynamics modify the rat pulmonary artery response to injury. A neointimal model of pulmonary hypertension. Am J Pathol 151: 1019-1025. [Crossref]

29. Tanaka Y, Schuster DP, Davis EC, Patterson GA, Botney MD (1996) The role of vascular injury and hemodynamics in rat pulmonary artery remodeling. $J$ Clin Invest 98: 434-442. [Crossref]

30. White RJ, Meoli DF, Swarthout RF, Kallop DY, Galaria II, et al. (2007) Plexiformlike lesions and increased tissue factor expression in a rat model of severe pulmonary arterial hypertension. Am J Physiol Lung Cell Mol Physiol 293: L583-L590. [Crossref]

31. Dorfmüller P, Chaumais MC, Giannakouli M, Durand-Gasselin I, Raymond N, et al (2011) Increased oxidative stress and severe arterial remodeling induced by permanent high-flow challenge in experimental pulmonary hypertension. Respir Res 12:119.

32. van Albada ME, Schoemaker RG, Kemna MS, Cromme-Dijkhuis AH, van Veghel $\mathrm{R}$, et al. (2005) The role of increased pulmonary blood flow in pulmonary arterial hypertension. Eur Respir J 26: 487-493. [Crossref]

33. Morimatsu Y, Sakashita N, Komohara Y, Ohnishi K, Masuda H, et al. (2012) Development and characterization of an animal model of severe pulmonary arterial hypertension. J Vasc Res 49: 33-42. [Crossref]

34. Coste F, Guibert C, Magat J, Abell E, Vaillant F, et al. (2017) Chronic hypoxia aggravates monocrotaline-induced pulmonary arterial hypertension: a rodent relevant model to the human severe form of the disease. Respir Res 18: 47. [Crossref]

35. Huang J, Wolk JH, Gewitz MH, Loyd JE, West J, et al. (2015) Enhanced caveolin-1 expression in smooth muscle cells: Possible prelude to neointima formation. World $J$ Cardiol 7: 671-684. [Crossref]

36. Patel HH, Zhang S, Murray F, Suda RY, Head BP, et al. (2007) Increased smooth muscle cell expression of caveolin-1 and caveolae contribute to the pathophysiology of idiopathic pulmonary arterial hypertension. FASEB J 21: 2970-2979. [Crossref]

37. Taraseviciene-Stewart L, Kasahara Y, Alger L, Hirth P, Mc Mahon G, et al. (2001) Inhibition of the VEGF receptor 2 combined with chronic hypoxia causes cell deathdependent pulmonary endothelial cell proliferation and severe pulmonary hypertension. FASEB J 15: 427-438. [Crossref]

38. Abe K, Toba M, Alzoubi A, Ito M, Fagan KA, et al. (2010) Formation of plexiform lesions in experimental severe pulmonary arterial hypertension. Circulation 121: 27472754. [Crossref]

39. De Raaf MA, Schlij I, Gomez-Arroyo J, Rol NI, Happé CI et al. (2014) SuHX rat model: partly reversible pulmonary hypertension and progressive intima obstruction. Eur Respir J 44:160-168. [Crossref] 
40. Abe K, Shinoda M, Tanaka M, Kuwabara Y, Yoshida K, et al. (2016) Haemodynamic unloading reverses occlusive vascular lesions in severe pulmonary hypertension. Cardiovasc Res 111: 16-25. [Crossref]

41. Heath D, Donald DE, Edwards JE (1959) Pulmonary vascular changes in a dog after aortopulmonary anastomosis for four years. Br Heart J 21:187-196. [Crossref]

42. Esterly JA, Glagov S, Ferguson DJ (1968) Morphogenesis of intimal obliterative hyperplasia of small arteries in experimental pulmonary hypertension. An ultrastructural study of the role of smooth-muscle cells. Am J Pathol 52: 325-347. [Crossref]

43. Ferguson DJ, Varco RL (1955) The relation of blood pressure and flow to the development and regression of experimentally induced pulmonary arteriosclerosis. Circ Res 3: 152-158. [Crossref]

44. Geer JC, Glass BA, Albert HM (1965) The morphogenesis and reversibility of experimental hyperkinetic pulmonary vascular lesions in dog. Exp Mol Pathol 4: 399415. [Crossref]

45. Rothman A, Wiencek RG, Davidson S, Evans WN, Restrepo H, et al. (2011) Hemodynamic and histologic characterization of a swine (Sus scrofa domestica) model of chronic pulmonary arterial hypertension. Comp Med 61: 258-262. [Crossref]

46. Corno AF, Tozzi P, Genton CY, von Segesser LK (2003) Surgically induced unilateral pulmonary hypertension: time-related analysis of a new experimental model. Eur $J$ Cardiothorac Surg 23: 513-517. [Crossref]

47. Bousamra M, Rossi R, Jacobs E, Parviz M, Busch C, et al. (2000) Systemic lobar shunting induces advanced pulmonary vasculopathy. J Thorac Cardiovasc Surg 120: 88-98. [Crossref]

48. Ghobadi G, Bartelds B, van der Veen SJ, Dickinson MG, Brandenburg S, et al. (2012) Lung irradiation induces pulmonary vascular remodelling resembling pulmonary arterial hypertension. Thorax 67: 334-341. [Crossref]

49. Mathew R (2011) Pulmonary Hypertension: Endothelial cell Function. In Pulmonary hypertension: From Bench Research to Clinical Challenge (pp 1-24). Editors: Sulica R and Preston I. Publishers: Intech 2011: ISBN 978-953-307-835-9

50. Mathew R (2011) Cell-specific dual role of caveolin-1 in pulmonary hypertension. Pulm Med 2011: 573432. [Crossref]

51. Mathew R (2012) PDGF receptor blocker for pulmonary hypertension: a new agent in therapeutic arsenal. Expert Opin Investig Drugs 21:139-142. [Crossref]

52. Bull TM, Golpon H, Hebbel RP, Solovey A, Cool CD, et al. (2003) Circulating endothelial cells in pulmonary hypertension. Thromb Haemost 90: 698-703. [Crossref]

53. Lévy M, Bonnet D, Mauge L, Celermajer DS, Gaussem P, et al. (2013) Circulating endothelial cells in refractory pulmonary hypertension in children: markers of treatment efficacy and clinical worsening. Plos One 8: e65114. [Crossref]
54. Mathew R (2014) Pathogenesis of pulmonary hypertension: a case for caveolin-1 and cell membrane integrity. Am J Physiol Heart Circ Physiol 306: H15-25. [Crossref]

55. Zhao YY, Liu Y, Stan RV, Fan L, Gu Y, et al. (2002) Defects in caveolin-1 cause dilated cardiomyopathy and pulmonary hypertension in knockout mice. Proc Natl Acad Sci USA 99:11375-11380. [Crossref]

56. Murata T, Lin MI, Huang Y, Yu J, Bauer PM, et al. (2007) Reexpression of caveolin-1 in endothelium rescues the vascular, cardiac, and pulmonary defects in global caveolin-1 knockout mice. J Exp Med 204: 2373-2382. [Crossref]

57. Austin ED, Ma L, LeDuc C, Berman Rosenzweig E, Borczuk A, et al. (2012) Whole exome sequencing to identify a novel gene (caveolin-1) associated with human pulmonary arterial hypertension. Circ Cardiovasc Genet 5: 336-343. [Crossref]

58. Belo VA, Guimarães DA, Castro MM (2015) Matrix Metalloproteinase 2 as a Potentia Mediator of Vascular Smooth Muscle Cell Migration and Chronic Vascular Remodeling in Hypertension. J Vasc res 52: 221-231. [Crossref]

59. Lepetit H, Eddahibi S, Fadel E, Frisdal E, Munaut C, et al. (2005) Smooth muscle cell matrix metalloproteinases in idiopathic pulmonary arterial hypertension. Eur Respir $J$ 25: 834-842. [Crossref]

60. Mathew R, Huang J, Katta US, Krishnan U, Sandoval C, et al. (2011) Immunosuppressant-induced endothelial damage and pulmonary arterial hypertension. J Pediatr Hemetol Oncol 33:55-58. [Crossref]

61. Dereddy N, Huang J, Erb M, Guzel S, Wolk JH, et al. (2012) Associated inflammation or increased flow-mediated shear stress, but not the pressure alone disrupts endothelial caveolin-1 in infants with pulmonary hypertension. Pulm Circ 2: 492-500. [Crossref]

62. Huber LC, Soltermann A, Fischler M, Gay S, Weder W, et al. (2009) Caveolin-1 Expression and Hemodynamics in COPD Patients. Open Respir Med J 3: 73-78. [Crossref]

63. Sakao S, Taraseviciene-Stewart L, Lee JD, Wood K, Cool CD, et al. (2005) Initial apoptosis is followed by increased proliferation of apoptosis-resistant endothelial cells. FASEB J 19: 1178-1180. [Crossref]

64. Lévy M, Maurey C, Celermajer DS, Vouhé PR, Danel C, et al. (2007) Impaired apoptosis of pulmonary endothelial cells is associated with intimal proliferation and irreversibility of pulmonary hypertension in congenital heart disease. J Am Coll Cardiol 49:803-810. [Crossref]

65. Tuder RM, Chacon M, Alger L, Wang J, Taraseviciene-Stewart L, et al. (2001) Expression of angiogenesis-related molecules in plexiform lesions in severe pulmonary hypertension: evidence for a process of disordered angiogenesis. J Pathol 195:367-374. [Crossref]

Copyright: (C2018 Mathew R. This is an open-access article distributed under the terms of the Creative Commons Attribution License, which permits unrestricted use, distribution, and reproduction in any medium, provided the original author and source are credited. 